\title{
Engine Isolate Mount Elastomers
}

\author{
Wang Peng*, Su Zhengtao, Lai Liangqing, Jiang Honggang, Wang Jinghe \\ Beijing Institute of Aeronautical Materials \\ Aviation Key Laboratory of Science and Technology on Materials and \\ Application Research for vibration and Noise Reduction \\ Beijing, China \\ sduwps@163.com
}

\begin{abstract}
Engine isolate mounts such as laminated high damping elastomeric bearings, commonly used in automotive and aerospace applications, provide a simple means of isolating the structure of car/aircraft from the engine motions. The key properties of the elastomer are dynamic modulus and damping. The effect of strain amplitude, repeated cycling, and temperature influence on these properties are also important to evaluate the potential engine isolate mount elastomers, such as natural rubber (NR), polybutadiene rubber (BR), Nitrile Rubber (NBR), epoxidized natural rubber (ENR), Neoprene (CR), Poly(Methyl Methacrylate (PMMA), polyurethane (PU), nanoclay-modified PU/polypropylene oxide-polyethylene oxide copolymer with LiClO4 20 wt\% (PEL) blends system, ethylene-propylene-diene monomer (EPDM)/nylon 6 blend systems, and so on. All above elastomers or corresponding composite materials and their vibration isolating properties, including the correlations between damping factor, energy loss, damping constant, and vibration transmissibility ratio, are introduced. As a result, the selection principles of elastomers for the engine isolate mount are provided.
\end{abstract}

Keywords—engine isolate mount; dynamic modulus; damping; elastomers; aircraft

\section{INTRODUCTION}

Engine isolate mounts are commonly used in automotive and aerospace applications to isolate the cabin from engine vibration [1]. It was applied for aircraft design since the 1940s, which following 3 principles, (1) vibration magnitude transferring from the engine to the cabin should be lowered to permitted value, (2) the natural frequency of engine isolate mount should avoid coupling with each natural frequency of the vehicle structure including the cabin, (3) the maximum vibration displacement amplitude of the engine should be limited within permitted gaps between engine and its attachment, pipes, wires, and surrounding structures [2]. To reduce cabin noise and vibration, the engine/engine mounting system natural frequencies (engine rigid body modes) are designed to below the engine idle speed. With the appropriate design of the six engine rigid body modes below the engine idle speed, the cabin can be isolated from the engine vibrations at higher frequencies. But the engine mount dynamic stiffness should be known for the operating frequency. In civil aviation applications, the engine mounts can operate as high as $1000 \mathrm{~Hz}$, and in some military application as high as $5000 \mathrm{~Hz}$. At such high frequencies, the isolate mounts no longer behave only as a spring but may have many internal modes [1]. Recent researches and development efforts have been focused on improving engine mounting technology to achieve better vibration isolation, smooth vehicle movement, and noise reduction with good compression set and aging properties [3].

Material development is a major contributor to the improvement of engine isolate mounts. New kinds of elastomer that permit specification of the amount of damping have been developed. Polymers that can withstand higher engine compartment temperatures have also been available. With the help of formulation and processing techniques, elastomers can provide specific dynamic properties and to improve the consistency of such properties with respect to the varying vehicle environment. However, the solely elastomeric mount can not handle the sophisticated combination of stiffness and damping required in the modern vehicle, which are important dynamic behaviors to represent the performance of an engine isolate mount system [1]. Therefore the hydraulic mount called fluid-filled elastomeric mount, which is a combination of a traditional elastomeric mount and a viscous damper, was developed. Moreover, some kinds of electromagnetism mount including active-control mechanism were also designed and provided especially for limousines and business aircraft. Although novel structures, new materials, and creative isolate mechanisms are developed following the developing of the vehicle, the elastomers such as rubber [3-10], plastic composite materials [11-13], and rubber/plastic composite materials [14, 15] occupy the dominate position of the engine isolate mount areas. The effect of strain amplitude, repeated cycling, and temperature influence on these properties are also important to evaluate the potential engine isolate mount elastomers. Such elastomers as NR, BR, NBR, ENR, CR, PMMA, PU, nanoclay-modified PU/PEL blend systems, ethylenepropylene-diene monomer/nylon 6 blend systems, and their vibration isolating properties are introduced.

\section{ENGINE ISOLATE MOUNT RUBBER}

Rubber is a kind of polymer material. Mixing with some other materials (filler, a vulcanizing agent, or oil) and applying heat and pressure, the molecular chains in rubber can chemically crosslink to each other. Such vulcanizing process can provide excellent elastic property for elastomer part of engine isolate mounts. There are two types of rubber used for the rubber engine isolate mount. One is the natural rubber (NR), which has an almost linear elastic behavior and a superior creep resistance. However, it should not be exposed to the atmosphere because this type of rubber can't tolerate under ozone environment. The other is high damping rubber, which is made from petroleum and exhibits non-linear behavior, and its 
characteristics can be modified for specific purposes by changing the ratio of the materials [16].

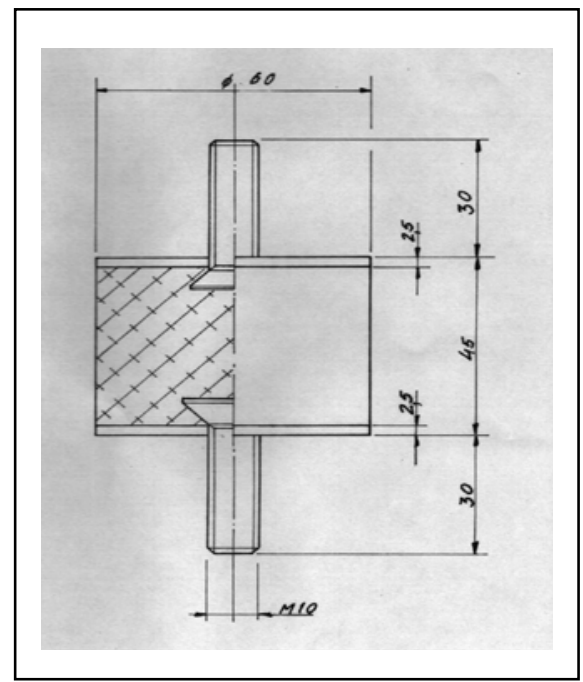

Fig. 1. The engine mount [4].

\section{A. NR}

The dynamic properties of rubber engine isolate mounts are very dependent on the rubber compound formulation. The effects of hybrid fillers of small particle size of carbon black, N220 and large particle size of carbon black, N774 (N220/N774) on mechanical and aging properties of NR composites were studied. The results indicts that the hybrid filler/NR composite material has shown an improved properties of engine mount compounds, with good compression and resilience characteristics attributed to the use of large carbon black particles while retaining the good elongation, modulus, and tensile strength attributable to the presence of small carbon black particles. High temperature evaluation results indicated that hybrid fillers have improved hardness, compression set and aging properties due to the higher retention properties [3]. Also, the effects of two grades of carbon black (N550 and N772) on the tear resistance and on the dynamic properties-spring rate ratio $\left(\mathrm{K}_{\mathrm{d}} / \mathrm{K}_{\mathrm{s}}\right)$ and tan $\delta$ - of rubber compounds based in NR and vulcanized with two different curing systems (normal and semi-efficient) are examined. Moreover, the dynamic properties are measured using a very simple engine mount (Fig. 1). The result indicts that with the semi-efficient curing system, the appropriate values of N550 and N772 are $25 \mathrm{phr}$ and $34.5 \mathrm{phr}$, respectively [4].

\section{B. NR/BR blend}

NR is known for its inherent strength, its ability to withstand large deformations and resistance to crack propagation. BR, on the other hand, exhibits better abrasion resistance, resilience, and resistance to initiation of cracks. Therefore, a combination of NR and BR finds vast application in various rubber products, including the tread and sidewall of the tyre and elastomer part the engine isolate mount $[6,7]$. The influences of the temperature history on the Mullins effect of NR/BR blend, recovery behavior, and the rate dependence are experimentally investigated. To study the influence of low temperatures and large deformations on the Mullins effect, cyclic strain-controlled processes are applied under different temperatures. The results indicate that the material behavior of the NR/BR rubber blend does not depend only on the deformation history and the current thermodynamic temperature, but also on the entire temperature history. In addition, healing effect exists in such history [6].

\section{ENR/CR Blend}

Because of their highly damping properties, ENR and CR were blended with various blending ratios. The dynamic mechanical properties, hysteresis, and vibration transmissibility ratio (Tr) of the vulcanized ENR/CR blends were measured. Such results are used to evaluate the antivibration and vibration isolation performance through the study of the correlations between damping factor $(\tan \delta)$, energy loss $(\Delta W)$, damping constant $(\beta)$, and vibration transmissibility ratio. The loss energy $\Delta W$, damping constant $\beta$, and $\tan \delta$, from compressive hysteresis, are summarized in Tables I. The effect of $\tan \delta$ on $T r$ and the damping factor $(\xi)$ for $\mathrm{ENR} / \mathrm{CN}$ blends at $20^{\circ} \mathrm{C}$ is shown in Fig. 2. From where can we see that $\xi$ increases with $\tan \delta$. Such correlations are helpful for future design of suitable blends for the purposes of antivibration and vibration isolation. Based on transmissibility ratio results, CR shows better performance in antivibration than ENR [8].

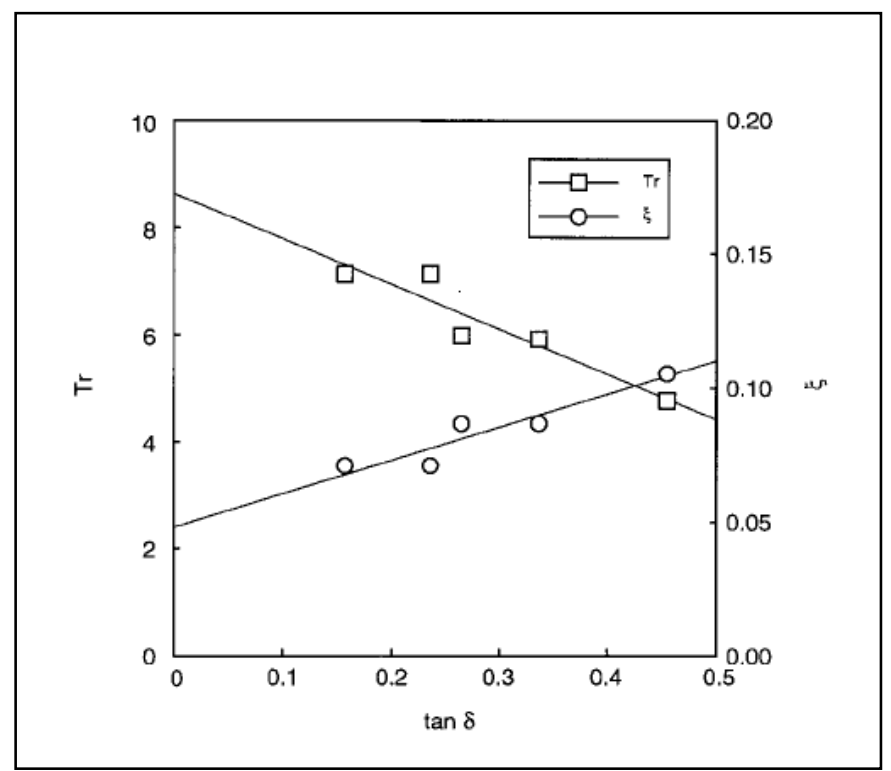

Fig. 2. The effect of $\tan \delta$ on $\operatorname{Tr}$ and $\xi$ of ENR/CR blends [8].

TABLE I. PROPERTY OF ENR/CR BLENDS UNDER COMPRESSEION STRAIN [8]

\begin{tabular}{|l|c|c|c|c|c|}
\hline Property $^{\mathrm{a}}$ & $\begin{array}{c}\text { EC1 } \\
\mathbf{( 1 0 0 / 0 )}\end{array}$ & $\begin{array}{c}\text { EC2 } \\
\mathbf{( 7 5 / 2 5 )}\end{array}$ & $\begin{array}{c}\text { EC3 } \\
\mathbf{( 5 0 / 5 0 )}\end{array}$ & $\begin{array}{c}\text { EC4 } \\
\mathbf{( 7 5 / 2 5 )}\end{array}$ & $\begin{array}{c}\text { EC5 } \\
\mathbf{( 0 / 1 0 0 )}\end{array}$ \\
\hline$\Delta \mathrm{W}(\mathrm{J})$ & 0.3134 & 0.2284 & 0.1880 & 0.1823 & 0.1714 \\
\hline$\beta$ & 0.2136 & 0.1726 & 0.1710 & 0.1422 & 0.1410 \\
\hline $\tan \delta$ & 0.4541 & 0.3533 & 0.2623 & 0.2357 & 0.1565 \\
\hline
\end{tabular}




\section{Dynamic and antivibration reliability properties of rubber}

Many kinds of rubber and their blends with different radio are applied in isolate mounts. Their dynamic and antivibration properties, such as $\mathrm{K}_{\mathrm{d}} / \mathrm{K}_{\mathrm{S}}$, damping at room temperature (RT) and $100{ }^{\circ} \mathrm{C}$, dynamic elasticity modulus $\left(\mathrm{E}_{\mathrm{d}}\right)$ at $100{ }^{\circ} \mathrm{C}$, dynamic elasticity modulus change $\left(\Delta \mathrm{E}_{\mathrm{d}}\right)$ at $-30{ }^{\circ} \mathrm{C}$, and aging properties, were listed in Table II [9]. According to Table II, diene rubber, including NR, BR, and SBR, is the best choice for engine isolate mounts in general application. Moreover, the silicon rubber $(\mathrm{Q})$ is suitable for extreme temperature applications as well as that the NBR is better for oil environment [10].

TABLE II. DYNAMIC AND ANTIVIBRATION RELIABILITY PROPERTIES OF RUBBER [9]

\begin{tabular}{|c|c|c|c|c|c|c|}
\hline Property $^{a}$ & NR & BR & SBR & CR & NBR & $\mathbf{Q}$ \\
\hline Low $\mathrm{K}_{\mathrm{d}} / \mathrm{K}_{\mathrm{s}}(\mathrm{RT})$ & +++ & +++ & + & - & - & ++ \\
\hline Damping(RT) & + & + & ++ & ++ & ++ & + \\
\hline $\mathrm{E}_{\mathrm{d}}\left(100^{\circ} \mathrm{C}\right)$ & ++ & ++ & + & + & + & +++ \\
\hline Damping $\left(100^{\circ} \mathrm{C}\right)$ & ++ & ++ & + & + & + & ++ \\
\hline$\Delta \mathrm{E}_{\mathrm{d}}\left(-30^{\circ} \mathrm{C}\right)$ & ++ & ++ & ++ & + & - & +++ \\
\hline $\begin{array}{ll}\text { resistance } & \text { to } \\
\text { pressure (RT) } & \end{array}$ & +++ & +++ & ++ & + & + & + \\
\hline $\mathrm{E}_{\mathrm{S}}\left(100^{\circ} \mathrm{C}\right)$ & ++ & ++ & ++ & + & + & ++ \\
\hline $\begin{array}{l}\text { Dynamic } \\
\text { properties change } \\
\text { after aging }\left(100^{\circ} \mathrm{C}\right. \\
\times 240 \mathrm{~h})\end{array}$ & + & + & ++ & + & + & ++ \\
\hline $\begin{array}{l}\text { fatigue } \\
\text { performance after } \\
\text { aging }\left(100^{\circ} \mathrm{C} \times\right. \\
240 \mathrm{~h})\end{array}$ & + & + & + & + & + & ++ \\
\hline
\end{tabular}

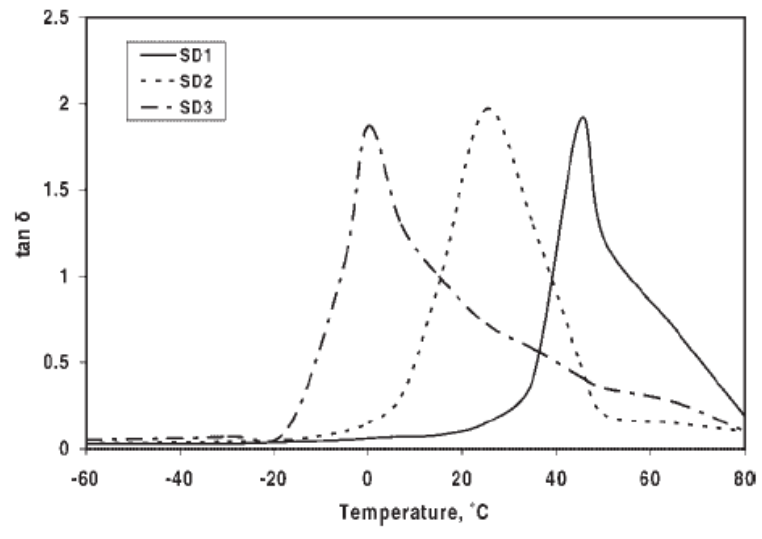

Fig. 3. Plot of loss tangent v. temperature of three EP materials [12].

\section{ENGINE ISOLATE MOUNT PLASTIC COMPOSITE MATERIAL}

\section{A. $\quad P U$}

PU elastomers based on polyester diols and aromatic or aliphatic diisocyanates can be used as vibration dampers and isolation material. Two series of cross-linked polyurethanes with various hard segment structures and different amounts and their thermo-mechanical properties were studied. The experiment results show that the cross-link and the polyurethane hard segment interaction play a special role in the interconnected chain density and its magnitude is revealed by the mechanical properties. Cross-linked polyurethane behaves as an elastomer and is useful for vibration control [11].

\section{B. $E P$}

EP resin is a class of versatile thermosetting polymers, which are widely used as structural adhesives, composites, surface coatings and laminates because of their high strength, low creep, extremely low cure shrinkage and excellent resistance to corrosion, high adhesive strength to many substrates and appropriate electrical properties. However, sharp and high $\mathrm{T}_{\mathrm{g}}$ values (in the range of $60-120^{\circ} \mathrm{C}$ ) make it unfeasible to be used as damping materials in the room temperatures and frequencies of interest. By using polyether amine hardeners having varying chain lengths of polyether, three new epoxy composite materials with low $\mathrm{T}_{\mathrm{g}}\left(0-45^{\circ} \mathrm{C}\right.$, Fig 3 ) were developed. Excellent dynamic mechanical properties couple with satisfactory mechanical properties and less weight penalty on application signify their value as viscoelastic materials in engine isolate mounts [12].

\section{Nanoclay-modified PU/PEL blends}

The incorporation of clay and organoclay in the PU/PEL blends can form the material with random nanoscale sandwich structures. Such material has high stiffness, optimum antivibration, and vibration isolation properties, proved by dynamic mechanical analysis (DMA), hysteresis phenomenon, and dynamic properties tests. The compressive vibration hysteresis study indicates that the area of the hysteresis loop increased with increasing content of organically modified clay, produce a better antivibration effect. From the relational cure of dynamic ratio and $\tan \delta$, the blends containing $6-10 \mathrm{wt} \%$ of clay exhibit higher $\tan \delta$ and lower dynamic ratio, suggesting that the addition of clay gives the blends better antivibration and vibration isolation effects [13].

\section{ENGINE ISOLATE MOUNT RUBBER/PLASTIC COMPOSITE MATERIALS}

\section{A. EPDM/nylon 6 blends}

Rubber/plastic blends have been commercialized as thermoplastic elastomers (TPEs). Thermoplastic vulcanizates (TPVs) form a special class of TPEs that can be processed under molten conditions as a thermoplastic polymer at elevated temperatures, at which the rubber phase is vulcanized with suitable curatives during mixing with a thermoplastic polymer.

The EPDM/ nylon blends (TPVs) prepared by the dynamic vulcanization process were evaluated by the determination of 
the mechanical properties and hysteresis behavior. The mechanical properties of TPV are found to be inferior to those of TPE materials, with the incompatible problem between EPDM rubber and nylon 6 plastic materials. The antivibration properties of TPV materials have been proven to be better than those of the TPE material system. Also, the dynamic vulcanization and nylon 6 content play important roles in the design of materials in terms of their vibration isolation and antivibration performance [14].

\section{B. NBR/PMMA blends}

Interpenetrating polymer networks (IPNs) are a branch of polyblends having interlocking structure without a covalent bond between the constituent polymers. Application of such polymers to vibrating substrates leads to a reduction of mechanical vibrations, which minimizes transmitted noise and decreases substrate fatigue. IPNs based on NBR and PMMA were varied by varying the swelling time. At 62/38 NBR/PMMA multistep IPN (MIPN), the $\tan \delta$ curve showed the isolation of peaks around $\mathrm{T}_{\mathrm{g}}$ of NBR and PMMA, respectively. It appeared that there is the isolation of some components during repeated swelling in monomer and subsequent curing. It indicates that graded damping can be achieved by using a combination of two or more monomers via the MIPN route [15].

\section{CONCLUSION}

(1) Although plastic composite materials are developed following the developing of material science, rubber and rubber/plastic composite material still occupy the dominate position of the engine isolate mount areas.

(2) The selection of optimum elastomer for an engine isolate mount is not straightforward. The correlations between damping factor $(\tan \delta)$, energy loss (Dleta $W$ ), damping constant $(\beta)$, and vibration transmissibility ratio should be considered, comprehensively.

(3) The dynamic mechanical properties of the elastomers are determined as a function of frequency and strain amplitude. The anti-fatigue properties and adaptability to the environment such as temperature and contacted media should also be considered.

\section{REFERENCES}

[1] N. Vahdati, and L.K.L. Saunders, "High frequency testing of rubber mounts," ISA transction, vol. 41, pp. 145-154, June 2002

[2] Y.H. Chen, H.L. Wang, E.D. Su, C.L. Chen, and K.X. Li, "Design Method of Aeroengine Rubber Vibration Isolator," Science Technology and Engineering, vol. 13, pp. 5889-5893, July 2013.

[3] A.A. Rashid, and S.R. Yahya, "Mechanical and ageing properties of hybrid carbon black filled natural rubber composites for engine mount application," 6th Asian-Australasian Conference on Composite Materials: Progress of Composites 2008 in Asia and Australasia, ACCM 2008, pp. 300-303, September 2008.

[4] M.J.M. Gomes, and A.S. Pouzada, "Dynamic behaviour of rubber compounds for engine mounts," Key Engineering Materials, vol. 230232, pp. 303 - 306, October 2002.

[5] P. Ghosh, R. Stocek, M. Gehde, R. Mukhopadhyay, and R. Krishnakumar, "Investigation of fatigue crack growth characteristics of NR/BR blend based tyre tread compounds," International Journal of Fracture, vol. 188, pp. 9-21, April 2014.
[6] A.F.M.S. Amin, A. Lion, and P. Höfer, "Temperature history effects in rubber: literature review and critical experiments," ZAMMZEITSCHRIFT FUR ANGEWANDTE MATHEMATIK UND MECHANIK, vol. 90, pp. 347 - 369, April 2010.

[7] A. Ueda, T. Ohyama, H. Watanabe, and A. Yoshioka, "Vibration isolation characteristics of chemically modified solution-polymerized rubbers for engine mount use," Journal of Applied Polymer Science, vol. 44, pp. 229 - 241, March 1989.

[8] H.T. Chiu, T.C. Cheng, M.C. Yang, and W.G. Hwang, "Antivibration and Vibration Isolation of ENR/CR Blends," Advances in Polymer Technology, vol. 17, pp. 329-338, June 1998.

[9] A. Li, and H.D. Liu, "About antivibration and antivibration rubber," World Rubber Industry, vol. 39, pp. 6-11, February 2012.

[10] J.F. Yang, X.R. Zhou, and W. Ding, "Analysis of Oil-retarding Property of Damping Rubber," Noise and Vibration Control, vol. 33, pp. 50-58, Augest 2013.

[11] S. Oprea, "Structure and Properties of Cross-Linked Polyurethane Copolymers," Advances in Polymer Technology, vol.28, pp. 165-172, Augest 2009.

[12] D. Ratna, N.R. Manoj, L. Chandrasekhar, and B.C. Chakraborty, "Novel epoxy compositions for vibration damping applications," Polymers for Advanced Technologies, vol. 15, pp. 583-586, Augest 2004.

[13] H.T. Chiu, J.H. Wu, and Z.J. Shong, "Dynamic Properties of Rubber Vibration Isolators and Antivibration Performance of NanoclayModified PU/PEL Blends System," Polymer Engineering and Science, vol. 45, pp. 539-548, April 2005.

[14] J.H. Wu, C.H. Li, H.T. Chiu, and Z.J. Shong, "Dynamic Properties of Rubber Vibration Isolators and Antivibration Performance of EthylenePropylene-Diene Monomer/Nylon 6 Blend Systems," Journal of Applied Polymer Science, vol. 108, pp. 4114-4121, March 2008.

[15] A.B. Samui, V.G. Dalvi, M. Patri, B.C. Chakraborty, and P.C. Deb, "Studies on Semi-Interpenetrating Polymer Network Based on Nitrile Rubber and Poly(Methyl Methacrylate)," Journal of Applied Polymer Science, vol. 91, pp. 354-360, April 2003.

[16] I. Mangerig, and T. Mano, "Characteristics of various elastomeric bearings in tension," Steel Construction, vol. 2, pp. 161-166, September 2009 
